Research article

\title{
High abundance synovial fluid proteome: distinct profiles in
} health and osteoarthritis

\author{
Reuben Gobezie ${ }^{1}$, Alvin Kho' ${ }^{1}$, Bryan Krastins ${ }^{1}$, David A Sarracino', Thomas S Thornhill, \\ Michael Chase ${ }^{1}$, Peter J Millett ${ }^{1}$ and David M Lee ${ }^{1,2}$
}

\author{
1The Case Center for Proteomics, Case Western Reserve University School of Medicine, Euclid Avenue, Cleveland, Ohio 44106, USA \\ 2Department of Rheumatology, Brigham and Women's Hospital, Harvard Medical School, Boston, MA 02115, USA \\ Corresponding author: Reuben Gobezie, reuben.gobezie@uhhs.com \\ Received: 16 Jan 2007 Revisions requested: 8 Feb 2007 Revisions received: 6 Mar 2007 Accepted: 2 Apr 2007 Published: 2 Apr 2007 \\ Arthritis Research \& Therapy 2007, 9:R36 (doi:10.1186/ar2172) \\ This article is online at: http://arthritis-research.com/content/9/2/R36 \\ (C) 2007 Gobezie et al.; licensee BioMed Central Ltd. \\ This is an open access article distributed under the terms of the Creative Commons Attribution License (http://creativecommons.org/licenses/by/2.0), \\ which permits unrestricted use, distribution, and reproduction in any medium, provided the original work is properly cited.
}

\begin{abstract}
The development of increasingly high-throughput and sensitive mass spectroscopy-based proteomic techniques provides new opportunities to examine the physiology and pathophysiology of many biologic fluids and tissues. The purpose of this study was to determine protein expression profiles of high-abundance synovial fluid (SF) proteins in health and in the prevalent joint disease osteoarthritis (OA). A cross-sectional study of 62 patients with early OA $(n=21)$, patients with late OA $(n=21)$, and control individuals $(n=20)$ was conducted. SF proteins were separated by using one-dimensional PAGE, and the in-gel digested proteins were analyzed by electrospray ionization tandem mass spectrometry. A total of 362 spots were examined and 135 high-abundance SF proteins were identified as being expressed across all three study cohorts. A total of $135 \mathrm{SF}$ proteins were identified. Eighteen proteins were found to be
\end{abstract}

significantly differentially expressed between control individuals and OA patients. Two subsets of OA that are not dependent on disease duration were identified using unsupervised analysis of the data. Several novel SF proteins were also identified. Our analyses demonstrate no disease duration-dependent differences in abundant protein composition of SF in OA, and we clearly identified two previously unappreciated yet distinct subsets of protein profiles in this disease cohort. Additionally, our findings reveal novel abundant protein species in healthy SF whose functional contribution to SF physiology was not previously recognized. Finally, our studies identify candidate biomarkers for OA with potential for use as highly sensitive and specific tests for diagnostic purposes or for evaluating therapeutic response.

\section{Introduction}

Osteoarthritis (OA), which is characterized by progressive destruction of articular cartilage, is by far the most common musculoskeletal disorder in the world, afflicting 40 million people in the USA alone [1,2]. Although this disorder is one of the most common among the aging population, our understanding of its etiology and pathophysiology, as well as our ability to detect early disease, is strikingly poor. A number of factors have frustrated efforts to elucidate the disease, and to develop diagnostic and treatment approaches; these include conflicting observations in epidemiologic studies, protracted disease duration, poorly correlated symptoms and radiographic findings, and lack of effective therapies. Compounding these diffi- culties, experimental mouse models are lacking and diseased tissue for experimental analyses is typically obtained from patients with advanced disease at joint replacement surgery, thereby limiting insight to late stages of disease.

These challenges notwithstanding, extensive disease-focused research has revealed that $\mathrm{OA}$ is not simply the result of agerelated cartilage wear. Rather, the pathophysiology of disease involves the entire joint structure, including cartilage, synovium, ligaments, subchondral bone, and periarticular muscle. Documented contributors to this pathophysiology include genetic predisposition, trauma, inflammation, and metabolic changes. These insights have led many authorities to hypoth-

IGF = insulin-like growth factor; LC-MS/MS = liquid chromatography with tandem mass spectrometry; MMP = matrix metallproteinase; OA = osteoarthritis; $\mathrm{PCA}=$ principal component analysis; RAGE $=$ receptor for advanced glycation end-products; $\mathrm{SF}=$ synovial fluid. 
esize that $\mathrm{OA}$ is best thought of as a group of disorders with varied etiologies whose final common clinical phenotypes converge [3].

There exists a particular dearth of understanding of etiologic contributors in early OA pathophysiology and stage-specific events in disease progression. Because synovial fluid (SF) is in contact with the primary tissues affected by disease (cartilage and synovium) and has been implicated as a contributor to disease pathophysiology, we hypothesized that proteomic analysis of SF may provide a minimally invasive opportunity to derive further stage-specific insight into $O A$ disease. The advent of increasingly high-throughput and sensitive mass spectroscopy analytic methods and powerful statistical modeling, combined with exhaustive sequencing of the human genome, have facilitated unsupervised proteomic approaches to discovery of disease mechanisms. Here, we report on the results of a pilot cross-sectional study utilizing liquid chromatography with tandem mass spectrometry (LC-MS/MS) designed to identify differential expression of high-abundance SF proteins from healthy individuals and patients with earlystage and late-stage OA. Our analyses define a relative abundance of a large number of SF proteins and demonstrate that the protein composition of SF differs substantially between healthy individuals and patients with OA. Interestingly, although our data suggest that there is no significant change in the composition of high-abundance proteins between early and late $O A$, we identify distinct patterns of protein expression within OA patients that suggests identifiable subsets of disease that are independent of disease duration. Furthermore, we identify a panel of protein biomarkers that are of potential use in distinguishing SF from patients with OA from that of healthy study participants.

\section{Materials and methods}

The experimental design for this study involved differential protein profiling of knee SF, using LC-MS/MS, from 20 healthy control individuals and two cohorts of 21 patients diagnosed with early and late OA. All samples for the study were collected from patients within our tertiary care referral center. Our hospital's institutional review board approved all aspects of this study. All SF samples included in the study were snap-frozen in liquid nitrogen immediately after acquisition from the knee joint.

\section{Control individuals}

Twenty individuals without any prior history of knee trauma, chronic knee pain, prior knee surgery, blood dyscrasias, cancer, chondrocalcinosis, corticosteroid injection, or nonsteroidal anti-inflammatory drug use during the preceding eight weeks were recruited and underwent plain anterior-posterior, lateral, and sunrise view radiographs of their right/left knee. A total of 78 individuals qualified for entry into our study based on the criteria specified above and formed the study 'control' cohort. An arthrocentesis was attempted on each of these patients in order to obtain the 20 samples required for our study design. Samples that were free from visible blood contamination and consisted of a minimum of $500 \mu \mathrm{l}$ were included in the study.

\section{Patients with early osteoarthritis}

Samples were procured from 21 patients presenting for elective arthroscopic debridement of an inner-third tear of the medial meniscus with a minimum age of 45 years. Inner-third meniscal tears are relatively avascular, and therefore they are least likely to generate an inflammatory response that could confound proteomic analysis of protein expression related expressly to OA. No patients with a prior history of clinically significant knee trauma or infection, surgery, blood dyscrasia, cancer, corticosteroid injection, or chondrocalcinosis were included in the study. Because of the meniscal tear, prior nonsteroidal anti-inflammatory drug use was not a practical exclusion criterion. The diagnosis of early OA was made at the time of arthroscopy based on the presence of arthroscopically visible chondral erosion. SF was acquired at the time of arthroscopic trocar placement in order to avoid blood contamination of the samples.

\section{Patients with late osteoarthritis}

One SF sample was procured from each of 21 patients presenting for elective total knee replacement for management of primary idiopathic $\mathrm{OA}$. The exclusion criteria were identical to those for patients with early OA. Each patient had documented joint space narrowing of all three compartments of the knee on plain radiographs. The SF was acquired from the knee joint before arthrotomy so as to avoid blood contamination.

\section{Power analysis}

Supervised pair-wise comparisons were performed for each protein between the three disease classes (control: $n=20$; early OA: $n=21$; and late OA: $n=18$ ). Here, in the least optimal two-class comparison scenario, the two classes of sample size 18 (patients with late OA) and 20 (control individuals) possess a minimal statistical power of $80 \%$ at the 0.05 level of significance $(\alpha)$ to detect a $50 \%$ relative difference in the presence/abundance of a tested protein between classes. The null hypothesis was that there is no difference in the distribution of the tested protein's presence/abundance between the two classes.

\section{Reduction/alkylation of synovial fluid samples and electropheresis}

Each sample was reduced and alkylated in a lysis buffer before it was subjected to electrophoresis. Each sample was fractionated into nine molecular weight regions. An in-gel tryptic digestion was performed on the nine slices from each sample. After 24 hours of tryptic digestion, the peptides were extracted and lyophilized to dryness. The lyophilate was re-dissolved into a loading buffer for mass spectrometry. 


\section{Mass spectrometry}

Samples are run on a LCQ DECA XP plus Proteome $\mathrm{X}$ workstation (Thermo-Finnigan, Waltham, MA, USA). For each run (2.5 hours), half of each sample was separated on a $75 \mu \mathrm{m}$ (internal diameter) $\times 18 \mathrm{~cm}$ column packed with $\mathrm{C} 18$ media. In between each sample, a standard of a 5 Angio mix peptides was eluted (Michrom BioResources, Auburn, CA, USA) to ascertain column performance, and observe any potential carryover that might have occurred. The LCQ is run in a top five configuration, with one mass spectrometry scan and five tandem mass spectrometry scans.

\section{Processing of mass spectrometry data}

Mass spectrometric peptide sequence spectra were searched against the National Center for Biotechnology Information's RefSeqHuman database [4] with the addition of contaminants using SEQUEST [5]. Variable modifications for oxidized methione and carboxyamidomethylated cysteine were permitted. Data were filtered using the following criteria: Xcorr greater than or equal to $1.5,2.5$ and 3.0 for a charge state of 1,2 and 3 , respectively; a $\Delta \mathrm{Cn}$ greater than 0.1 ; and an $\mathrm{RSp}$ equal to 1. All peptides satisfying these criteria were then mapped back to all human protein sequences in RefSeq, with a string search for exact matches. For each gene identified within a gel slice a minimal (duplicates removed) set of peptides was identified. This list was sorted by the total number of peptides in descending order. The first peptide array in this list was defined as a cluster and compared pair-wise with every other array in the list by determining whether the $\mathrm{N}-1$ comparison was an equal or a proper subset. If the peptide array was found to be an equal or proper subset, then it was added to the cluster and removed from the list. The process was repeated until all comparisons were exhausted. For each cluster, the gene with the greatest number of peptide elements was assigned to designate the cluster. If multiple genes within the cluster had the same number of peptides, then an arbitrarily selected member was assigned as representative of the cluster. Peptides shared between clusters were identified and omitted from further analysis.

A total of 342 gel-slice distinct peptides were detected by LCMS/MS in the 62 samples in this study. Each sample was divided into nine protein gel slices. These 342 slice-distinct peptides are comprised of 135 unique Genlnfo accessionidentified proteins. Peptide area was used as the primary measure of protein abundance in the study. Peptide area was calculated using the area function in BioWorks 3.1 (Thermo Electron Corporation, Waltham, MA, USA) with scan window of 60 . Protein area was calculated as the sum of the areas for each independent analyte for all unique peptides within a protein cluster. If multiple areas were identified for a given analyte, then the largest area was selected and used in the in the area calculation. An independent analyte is defined as unique mass to charge identified in the SEQUEST search satisfying the filtering criteria.

\section{Principal component analysis}

Recalling that 342 slice-distinct peptides were assayed throughout the 62 samples in this study, each sample is represented as a mathematical vector of 342 feature components. Each feature component is the area readout of a specific gel slice-distinct peptide indicating the abundance of that peptide in the sample. The primary dataset is a 342-peptide $\times 62$-sample matrix of area readouts. Unsupervised principle component analysis (PCA) was used to assess the global sample variations and relationships in this dataset - between all 62 samples across 342 protein features - and to summarize the dataset in terms of a reduced number of dominant protein features that most affect the global sample variation [6-8]. Because we are using Pearson correlation as a measure of similarity between sample proteomic (area) profiles, each sample was normalized to have average 0 and variance 1 across its 342-feature protein areas before PCA. With area as a measure of slice-distinct protein abundance and sample profile similarity in terms of Pearson correlation, the first three principal components (PCs) capture $98.33 \%$ of global sample variation.

We note that the primary data matrix of 342 proteins $\times 62$ samples is sparse; 13,628 (about $64 \%$ ) of the 21,204 entries are 0 , and the remaining non-zero area entries (about 36\%) range from $10^{1}$ to $10^{6}$. Given this characteristic of the data, two samples may have a high Pearson correlation that is due, artifactually, to a small number of outlying (extremal) area readouts. To mollify the effect of these outliers in global sample variations, we additionally performed PCA on sample-wise rank-normalized data. For each sample, the area of each peptide is replaced with the ranking of the peptide's area from 1 to 342 (or multiples of $1 / 2$ within this range in cases where area values are identical) in relation to the areas of other peptides in that sample. Because we are using Pearson correlation as a measure of similarity between sample proteomic (area) profiles, each sample was normalized to have average 0 and variance 1 across its 342-feature peptide areas before PCA. With rank-normalized area as a measure of slice-distinct protein abundance and sample profile similarity in terms of Pearson correlation, the first three PCs capture $32.48 \%$ of global sample variation.

\section{Wilcoxon's rank sum test}

For each protein, the nonparametric Wilcoxon's ranksum test was used to assess whether the difference in medians between two disease conditions (control, early OA, and late $\mathrm{OA}$ ) of area measurements was statistically significant (whether the distributions of these area measurements overlap less than would be expected by chance) [9]. The null hypothesis is that the two independently measured conditions will be drawn from a single population, and therefore the medians will be equal. In this study, the null hypothesis (that a particular protein is differentially abundant) was rejected for $P<$ 0.000001 . 


\section{Results Synovial fluid protein profiles}

The proteins identified in our LC-MS/MS analyses are presented in Table 1. Note that 342 gel slice-distinct peptides, comprising a total cohort of 135 unique proteins, were detected across the 62 samples. Of these, 18 proteins represented keratin species (data not shown) that we considered to be contaminants from the cutaneous puncture performed during arthrocentesis and so removed them from further consideration, leaving a total of 117 SF proteins identified.

\section{Unsupervised principal component analysis of protein profiles}

To identify variations between samples in terms of global SF proteomic profile, we used PCA of the 62 samples across the 342 slice-distinct protein area measurements. The initial PCA on the protein area measurements of all 62 samples identified three late $O A$ sample profiles as statistical outliers from the remaining 59 samples (data not shown). These three outlier samples were removed from subsequent data analyses, leaving 342 slice-distinct proteins $\times 59$ samples in the dataset under consideration. PCA of the protein area measurements of this dataset revealed that the two maximal and important directions of sample variance, PCs 1 and 2 accounted for $90.35 \%$ of the total sample variance. Notable, in the PC1-PC2 plane, control individuals $(n=20)$ are more homogeneous than patients with early OA $(n=21)$ and those with late OA ( $n$ $=19$ ) in terms of global proteomic profile. The direction of maximal variance of $\mathrm{PC} 1$ correlates strongly with $\mathrm{OA}$ disease state.

Next, the protein area measurements of this dataset of 342 slice-distinct proteins $\times 59$ samples were rank-normalized for each sample (see Materials and methods, above) and PCA was performed on the resulting rank-normalized dataset. Similar to the protein area PCA, PCA of this dataset indicated that the control sample profiles were more homogeneous than the OA sample profiles (Figure 1). Although there was a clearer difference between the aontrol and OA sample profiles, this unsupervised analysis identified no definitive disease durationdependent difference in expression profiles of SF high-abundance proteins in OA patients (Figure 1). Interestingly, despite this lack of difference between early-stage and late-stage disease, the PCA of the rank-normalized protein area profiles revealed two distinct subpopulations among OA samples, which we denote as OA group $1(n=17)$ and OA group 2 ( $n$ $=21$ ). These two OA subpopulations do not appear to segregate by age, sex, ethnicity, or number of medications taken.

\section{Differentially abundant proteins in healthy versus osteoarthritis proteomic profiles}

We next sought to identify proteins that are differentially abundant (by area measures) between healthy individuals and patients with OA. Because the PCA analysis identified no significant difference between expression profiles from patients with early and late $\mathrm{OA}$, we pooled data from these two cohorts and performed supervised Wilcoxon's ranksum tests to identify unique proteins with differential abundance between the healthy and OA groups. This method identified a subset of 18 of the 342 total proteins analysed that met our cutoff value for differential expression ( $P<0.00001$; Figure 2 and Table 2). The small $P$ value used in this mathematical algorithm was chosen arbitrarily in order to reduce the number of candidate protein biomarkers identified to a manageable number that will appropriate for selective future study using more conventional techniques. Perhaps unsurprisingly, these 18 proteins are among the top 100 sample variation-contributing proteins in $\mathrm{PC} 1$ and $\mathrm{PC} 2$ in the previous PCA. Interestingly, a substantial majority (15/18) are significantly more abundant in the OA group than in the healthy group (Figure 2 and Table 2).

\section{Differentially abundant proteins in discrete osteoarthritis subsets}

Having identified two apparent subsets of patients with $O A$ in our unsupervised PCA of the rank-normalized protein area data, we conducted a supervised Wilcoxon ranksum test to identify differential protein expression between these OA subsets irrespective of disease duration. Using a highly significant $P$ value cutoff $(P<0.00005)$, we identified 12 proteins that exhibit differential expression between these OA subsets (Figure 3).

\section{Abundant synovial fluid proteins as potential biomarkers}

Having identified a subset of 18 proteins with significantly different expression levels between patients with $\mathrm{OA}$ and healthy control individuals, we proceeded to explore the sensitivity and specificity of these proteins as biomarkers for differentiating health from disease. Examining sensitivity and specificity of individual proteins demonstrated that several of the 18 proteins in this panel hold promise as potential biomarkers for distinguishing health from disease (Figure 2 and Table 2). Indeed, the best sensitivity and specificity for proteins in this subset was noted for complement component 3 , which exhibited sensitivity and specificity of $90 \%$ and $85 \%$, respectively.

\section{Discussion}

Although recent studies have highlighted the long appreciated importance of SF in joint function $[10,11]$, identification of the protein constituents of SF and elucidation of their function remain areas of active investigation. Advances in proteomic analytic techniques afford new opportunities to gain insight into the function of complex biologic fluids in health and disease. By using one-dimensional gel electropheresis and LC$\mathrm{MS} / \mathrm{MS}$, in the present study we provide quantitation of abundant proteins in SF in a cohort of 62 individuals, including healthy individuals and patients with early and late OA. Our results show clear differences in protein profiles between healthy and diseased SF, identify many SF proteins that are known to be involved in numerous homeostatic and pathologic 
Table 1

Synovial fluid proteins identified

\begin{tabular}{|c|c|}
\hline Gl\# & Protein \\
\hline 21493031 & A kinase (PRKA) anchor protein 13 \\
\hline 4501885 & Actin, beta \\
\hline 4501887 & Actin, gamma 1 \\
\hline 4501889 & Actin, gamma 2 , smooth muscle, enteric \\
\hline 4501987 & Afamin \\
\hline 6995994 & $\begin{array}{l}\text { Aggrecan } 1 \text { (chondroitin sulfate proteoglycan 1, large aggregating proteoglycan, antigen identified by monoclonal antibody } \\
\text { A0122) }\end{array}$ \\
\hline 4502027 & Albumin \\
\hline 55743106 & Alpha 3 type $\mathrm{VI}$ collagen isoform 5 precursor (NP_476508) \\
\hline 21071030 & Alpha-1-B glycoprotein \\
\hline 4502067 & Alpha-1-microglobulin/bikunin precursor \\
\hline 4502337 & Alpha-2-glycoprotein 1 , zinc \\
\hline 4502005 & Alpha-2-HS-glycoprotein \\
\hline 4557225 & Alpha-2-macroglobulin \\
\hline 40254482 & Amylase, alpha $1 \mathrm{~A}$; salivary \\
\hline 4502133 & Amyloid P component, serum \\
\hline 4557287 & Angiotensinogen (serine [or cysteine] proteinase inhibitor, clade A [alpha-1 antiproteinase, antitrypsin], member 8 ) \\
\hline 4502149 & Apolipoprotein A-II \\
\hline 4502151 & Apolipoprotein A-IV \\
\hline 4502153 & Apolipoprotein B (including Ag $[\mathrm{x}]$ antigen) \\
\hline 4502157 & Apolipoprotein C-I \\
\hline 32130518 & Apolipoprotein C-II \\
\hline 4502163 & Apolipoprotein D \\
\hline 4557325 & Apolipoprotein E \\
\hline 4557327 & Apolipoprotein $\mathrm{H}$ (beta-2-glycoprotein I) \\
\hline 4502397 & B-factor, properdin \\
\hline 4757826 & Beta-2-microglobulin \\
\hline 57634528 & Carboxypeptidase N, polypeptide 2, 83 kD (NP_001300 removed for review) \\
\hline 47777317 & Cartilage acidic protein 1 \\
\hline 51944962 & Cartilage intermediate layer protein (NP_003604) \\
\hline 40217843 & Cartilage oligomeric matrix protein \\
\hline 4557485 & Ceruloplasmin (ferroxidase) \\
\hline 42716297 & $\begin{array}{l}\text { Clusterin (complement lysis inhibitor, SP-40,40, sulfated glycoprotein 2, testosterone-repressed prostate message } 2 \text {, } \\
\text { apolipoprotein J) }\end{array}$ \\
\hline 42740907 & $\begin{array}{l}\text { Clusterin (complement lysis inhibitor, SP-40,40, sulfated glycoprotein 2, testosterone-repressed prostate message } 2 \text {, } \\
\text { apolipoprotein J) }\end{array}$ \\
\hline 4503635 & Coagulation factor II (thrombin) \\
\hline 15011913 & Collagen, type VI, alpha 1 \\
\hline 7705753 & Complement component 1 , q subcomponent, alpha polypeptide \\
\hline 11038662 & Complement component 1 , q subcomponent, beta polypeptide \\
\hline 56786155 & Complement component 1, q subcomponent, gamma polypeptide (NP_758957) \\
\hline 4502493 & complement component $1, \mathrm{r}$ subcomponent \\
\hline
\end{tabular}


Arthritis Research \& Therapy Vol 9 No 2 Gobezie et al.

Table 1 (Continued)

Synovial fluid proteins identified

\begin{tabular}{|c|c|}
\hline 41393602 & Complement component 1 , s subcomponent \\
\hline 14550407 & Complement component 2 \\
\hline 4557385 & Complement component 3 \\
\hline 4502501 & Complement component 4A \\
\hline 14577919 & Complement component 4A \\
\hline 50345296 & Complement component 4B preproprotein (NP_001002029) \\
\hline 38016947 & Complement component 5 \\
\hline 4559406 & Complement component 6 \\
\hline 45580688 & Complement component 7 \\
\hline 4557393 & Complement component 8 , gamma polypeptide \\
\hline 54792787 & Complement factor H-related 3 (NP_066303) \\
\hline 4885165 & Cystatin A (stefin A) \\
\hline 4503107 & Cystatin SA \\
\hline 42544239 & D component of complement (adipsin) \\
\hline 16751921 & Dermcidin \\
\hline 58530842 & Desmoplakin isoform II (NP_001008844) \\
\hline 11761629 & Fibrinogen, alpha chain isoform alpha preproprotein \\
\hline 4503689 & Fibrinogen, alpha chain isoform alpha-E preproprotein \\
\hline 11761631 & Fibrinogen, B beta polypeptide \\
\hline 4503715 & Fibrinogen, gamma chain isoform gamma-A precursor \\
\hline 11761633 & Fibrinogen, gamma chain isoform gamma-B precursor \\
\hline 47132557 & Fibronectin 1 isoform 1 preproprotein \\
\hline 47132551 & Fibronectin 1 isoform 2 preproprotein \\
\hline 16933542 & Fibronectin 1 isoform 3 preproprotein \\
\hline 47132555 & Fibronectin 1 isoform 4 preproprotein \\
\hline 47132553 & Fibronectin 1 isoform 5 preproprotein \\
\hline 47132549 & Fibronectin 1 isoform 6 preproprotein \\
\hline 4504165 & Gelsolin (amyloidosis, Finnish type) \\
\hline 6006001 & Glutathione peroxidase 3 (plasma) \\
\hline 32483410 & Group-specific component (vitamin D binding protein) \\
\hline 4504375 & $\mathrm{H}$ factor 1 (complement) \\
\hline 4826762 & Haptoglobin \\
\hline 45580723 & Haptoglobin-related protein \\
\hline 4504345 & Hemoglobin, alpha 1 \\
\hline 4504349 & Hemoglobin, beta \\
\hline 4504351 & Hemoglobin, delta \\
\hline 11321561 & Hemopexin \\
\hline 4504489 & Histidine-rich glycoprotein \\
\hline 4504579 & I factor (complement) \\
\hline 21489959 & Immunoglobulin J polypeptide, linker protein for immunoglob \\
\hline
\end{tabular}


Table 1 (Continued)

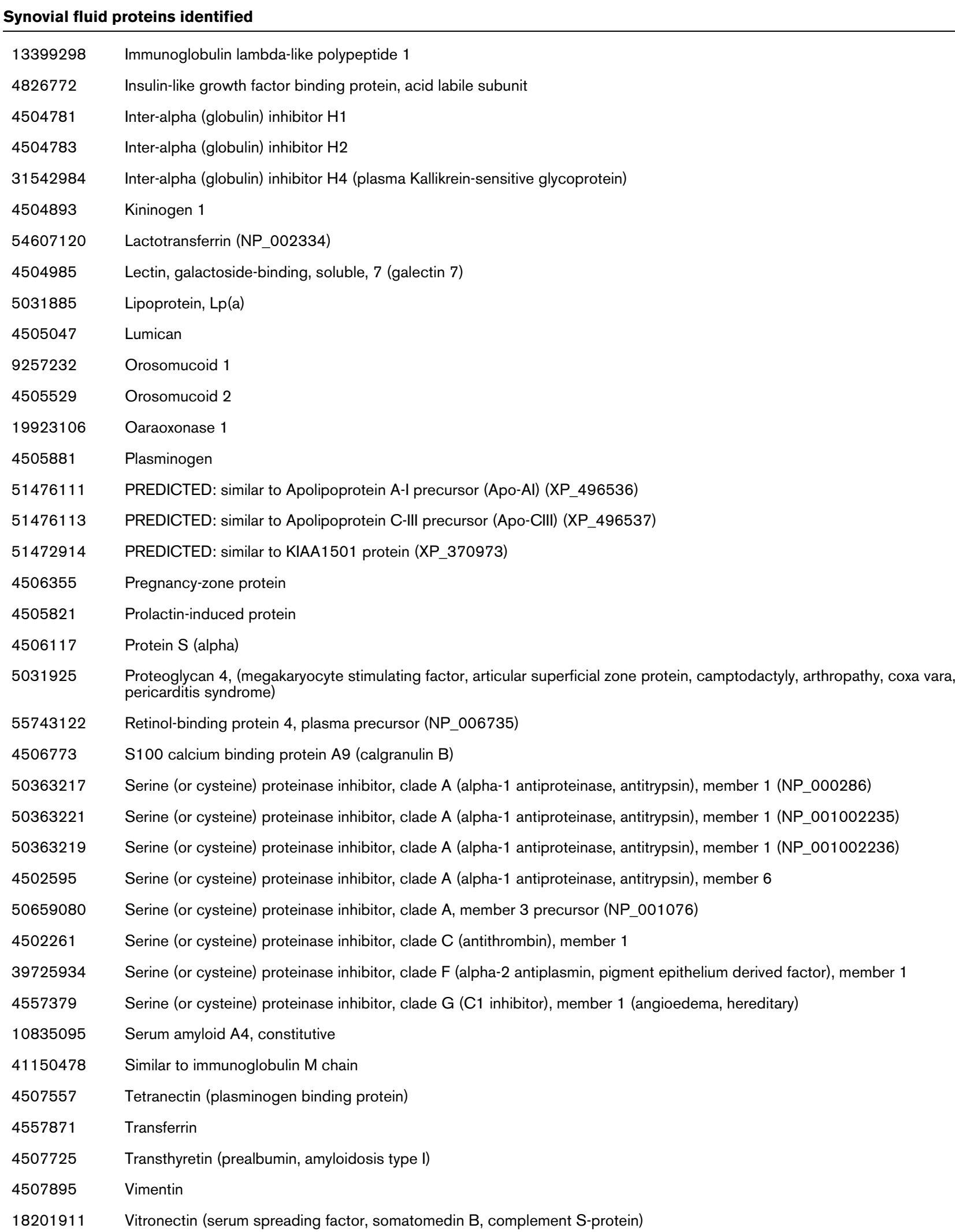


Figure 1

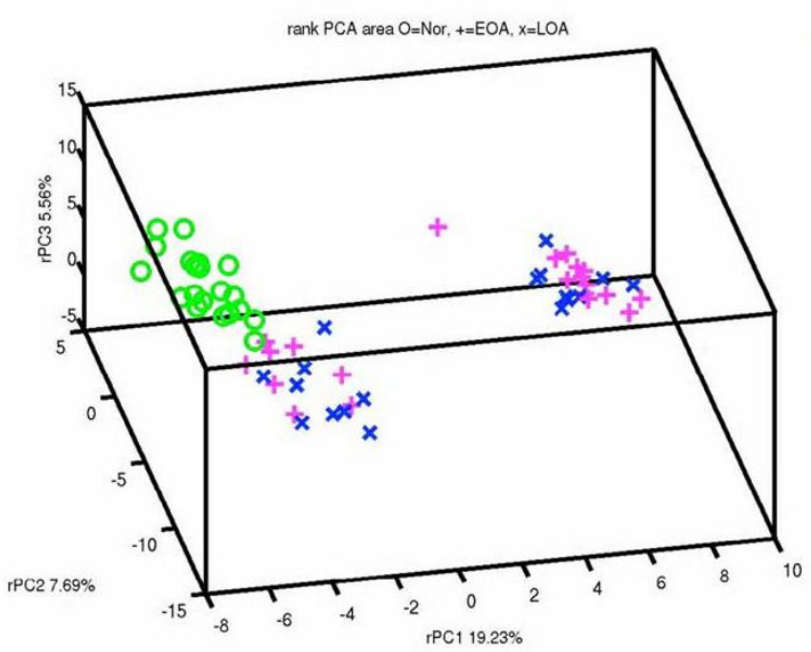

Principal component analysis of all 342 protein spots. Differential expression of the protein profile for healthy individuals versus patients with late and early osteoarthritis is observed using this unsupervised analytical technique. Note the two distinct subsets of protein expression in patients with osteoarthritis that cluster independently of disease duration. EOA, early osteoarthritis; LOA, late osteoarthritis; Nor, healthy individuals; PC, principal component; PCA, principal component analysis.

pathways, and - intriguingly - identify two distinct subpopulations of patients with $\mathrm{OA}$ whose membership occurs independently of disease duration. These data coupled with the MudPIT (multidimensional protein identification technology) quantitation technique allows us to predict relative levels of protein expression within the context of a onedimensional gel compared with a two-dimensional gel, as previously described [12-14].

Comparison of protein abundance between healthy individuals and $\mathrm{OA}$ patients identified 18 highly significant $(P<$ $0.000001)$ and a large number of less statistically significant differentially expressed proteins (Tables 1 and 2, and Figure 2 ), many of which were previously identified by other investigators. Of these 18 proteins, three exhibit decreased expression levels in OA patients whereas 13 are more abundant in OA than in healthy individuals (Figure 2 and Table 2). This differential profile provides potential insight into the pathophysiology of OA. Increased abundance of aggrecan and cystatin A in SF from healthy individuals is consistent with the current concept that loss of cartilage observed in OA results from proteolytic destruction of extracellular matrix [15-24]. It is particularly interesting that cystatin $A$, an inhibitor of cysteine proteases (for example, cathepsins), is elevated in healthy SF, whereas serine protease inhibitors, which are abundant in health and disease in our analyses and have been implicated in the pathogenesis of OA [21,25-27], are not among the panel of highly significant differentially expressed proteins. This observation provides a strong rationale for continued focus on the contri- bution of both classes of protease inhibitors to $\mathrm{OA}$ pathogenesis.

Dermcidin, the third abundant SF protein demonstrating increased expression in normal individuals as compared with OA patients is a novel antimicrobial peptide that was previously identified in human sweat [28]. Dermcidin peptides exhibit broad-spectrum antimicrobial activity against bacteria and fungal species, and are derived from post-translational and post-secretion processing by a series of proteases that are present in sweat glands $[28,29]$. To our knowledge, this is the first report to identify dermcidin expression in SF; the role of this protein in healthy joint physiology and the pathophysiologic consequences of decreased expression in OA require further investigation.

Somewhat surprisingly, examination for disease stage-specific (early versus late OA) differences in abundant protein expression using unsupervised analyses revealed no significant differences in these cohorts. Although it is likely that further analysis of low-abundance proteins may yield stage-specific patterns of protein composition in SF, this finding is consistent with the hypothesis that subsets of pathogenic mechanisms that contribute to OA disease initiation are present throughout the course of disease. This observation holds significant promise for both early identification of patients at risk for subsequent severe $\mathrm{OA}$ and for early therapeutic interventions to interrupt progression of disease.

Intriguingly, our unsupervised analyses identify two clearly distinct subpopulations of patients with OA that are independent of disease duration. Supervised (Wilcoxon ranksum test) analysis identified 12 protein species differentially populating the SF of these OA subsets. It is noteworthy that proteins present in blood comprise the entire cohort of proteins that contribute to identification of these OA subpopulations. This observation could result from differences in vascular permeability as a distinguishing pathophysiologic feature of a disease subset in patients with OA. However, most of these proteins were identified more recently as products of the cells within joint tissue: chondrocytes and synoviocytes [30,31]. Thus, the differences observed could also reflect differences resulting from $\mathrm{OA}$ joint physiology. Unfortunately, the design of this pilot study precludes examination of phenotypic differences in these subgroups. Utilizing these 12 species in future expanded longitudinal cohorts of OA patients will further clarify both the presence of disease phenotype subsets and the utility of quantifying these proteins in SF as a method of identifying OA subphenotypes for prognostic and therapeutic purposes.

Although a primary objective of our study was examination of differential protein expression of abundant SF proteins between healthy individuals and OA patients, our analyses also provide a wealth of information about the abundant protein composition of SF in health. Many of the proteins identi- 
Table 2

Significant differentially abundant proteins identified

\begin{tabular}{|c|c|c|c|c|c|}
\hline Gl\# & Protein description & Upregulated in & Specificity & Sensitivity & $\begin{array}{l}\text { Pvalue } \\
\text { (Fisher's exact, two sided) }\end{array}$ \\
\hline 4885165 & Cystatin A (stefin A) & Control & 0.650 & 1.000 & $1.92 \times \mathrm{e}^{-08}$ \\
\hline 6995994 & Aggrecan 1 (chondroitin sulfate proteoglycan 1) & Control & 0.650 & 0.974 & $2.30 \times \mathrm{e}^{-07}$ \\
\hline 1651921 & Dermcidin & Control & 0.600 & 1.000 & $1.13 \times \mathrm{e}^{-07}$ \\
\hline 4502027 & Albumin & $\mathrm{OA}$ & 0.950 & 0.718 & $7.96 \times \mathrm{e}^{-07}$ \\
\hline 4502067 & $\alpha_{1}$-Microglobulin/bikunin precursor & OA & 0.950 & 0.718 & $7.96 \times \mathrm{e}^{-07}$ \\
\hline 4503689 & Fibrinogen, $\alpha$ chain isoform $\alpha-E$ preprotein & $\mathrm{OA}$ & 0.950 & 0.718 & $7.96 \times \mathrm{e}^{-07}$ \\
\hline 4503715 & Fibrinogen, $\gamma$ chain isoform $\gamma$-A precursor & OA & 1.000 & 0.744 & $1.43 \times \mathrm{e}^{-08}$ \\
\hline 4557225 & $\alpha_{2}$-Macroglobulin & $\mathrm{OA}$ & 0.950 & 0.718 & $7.96 \times \mathrm{e}^{-07}$ \\
\hline 4557325 & Apolipoprotein E & OA & 1.000 & 0.744 & $1.43 \times \mathrm{e}^{-08}$ \\
\hline 4557327 & Apolipoprotein $\mathrm{H}$ ( $\beta_{2}$-glycoprotein I) & OA & 1.000 & 0.744 & $1.43 \times \mathrm{e}^{-08}$ \\
\hline 4557385 & Complement component 3 (gel slice 3) & $\mathrm{OA}$ & 0.950 & 0.718 & $7.96 \times \mathrm{e}^{-07}$ \\
\hline 4557385 & Complement component 3 (gel slice 5) & $\mathrm{OA}$ & 1.000 & 0.744 & $1.43 \times \mathrm{e}^{-08}$ \\
\hline 4557485 & Ceruloplasmin (ferroxidase) & OA & 0.950 & 0.718 & $7.96 \times \mathrm{e}^{-07}$ \\
\hline 4826762 & Haptoglobin & $\mathrm{OA}$ & 0.950 & 0.718 & $7.96 \times \mathrm{e}^{-07}$ \\
\hline 9257232 & Orosomucoid 1 & $\mathrm{OA}$ & 0.850 & 0.667 & $2.51 \times \mathrm{e}^{-04}$ \\
\hline 32483410 & Group specific component (vitamin D binding protein) & $\mathrm{OA}$ & 1.000 & 0.744 & $1.43 \times \mathrm{e}^{-08}$ \\
\hline 50345296 & Complement component 4B preprotein (NP_001002029) & $\mathrm{OA}$ & 1.000 & 0.744 & $1.43 \times \mathrm{e}^{-08}$ \\
\hline 5147611 & PREDICTED: similar to apolipoprotein A-1 precursor (apo-A-1; XP_496536) & OA & 0.950 & 0.718 & $7.96 \times \mathrm{e}^{-07}$ \\
\hline 55743122 & Retinol-binding protein 4, plasma precursor (NP_006735) & OA & 0.900 & 0.692 & $1.87 \times \mathrm{e}^{-05}$ \\
\hline
\end{tabular}

Eighteen proteins that were significantly differentially abundant (protein area) across control $(n=20)$ and OA ( $n=39)$ groups by Wilcoxon's ranksum test at $P<1 \times \mathrm{e}^{-06}$. Sensitivity/specificity for each protein are calculated with respect to the number of samples of each group having protein area above or below the median area across all samples. The significance of median area dichotomy and true group label is assessed by two-sided Fisher's exact test. Gl\#, Genlnfo accession.

fied have been implicated in pathways thought to contribute to the physiologic homeostasis of cartilage, synovial tissue, and SF. We consider these proteins within the context of the pathways with which they have previously been associated, in order to provide a synopsis of their potential biologic significance (Table 3).

\section{Serine protease inhibitors}

We identified numerous serine protease inhibitors in the SF of both healthy individuals and patients with diseasepatients (Table 3). The abundance and large number of species of serine proteinase inhibitors is consistent with the importance of the diverse and highly regulated functions of serine proteinases in joint function. Included among the host of physiologic processes in diarthrodial joints regulated by these species are regulation of matrix metalloproteinases (MMPs), aggrecanase, plasmin, tissue mitogens and angiogenesis activity, as well as inhibition of inflammatory leukocyte proteases such as neutrophil elastase and regulation of fibroblast mitogen binding to extracellular matrix [32-42]. Numerous lines of evidence demonstrate that synovial lining and cartilage extracellular matrix undergo active remodeling with joint homeostasis resulting from a delicate balance between matrix degradation, matrix synthesis, and matrix assembly [43]. The importance of this remodeling has been underscored by oncology trials of MMP inhibitors, whose side effects included a progressive polyarthritis with joint pain and stiffness [44-49]. Because the regulation and biologic function of a number of these serine proteinase inhibitors remains incompletely defined, our analyses provide further rationale for their continued study.

Inflammatory cascades and response to oxidative stress Oxidative damage and activation of mitogen-activated protein kinases have been reported to be involved in the pathogenesis of OA; our studies identify proteins implicated in these pathways as high-abundance species in SF. S100 activates the receptor for advanced glycation end-products (RAGE) $[50,51]$. Among the RAGE-stimulated mitogen-activated protein kinase downstream signaling cascades is the increased activity of nuclear factor- $\kappa \mathrm{B}$, which results in increased expression of MMPs and inflammatory mediators [52-55]. Afamin was recently identified as a novel vitamin $E$ binding protein [56]. Vitamin E confers protection from oxidative damage by scavenging reactive oxygen and nitrogen species [57]. Clusterin is produced in numerous tissues during tissue injury or in disease states, and has also been shown to be produced by 


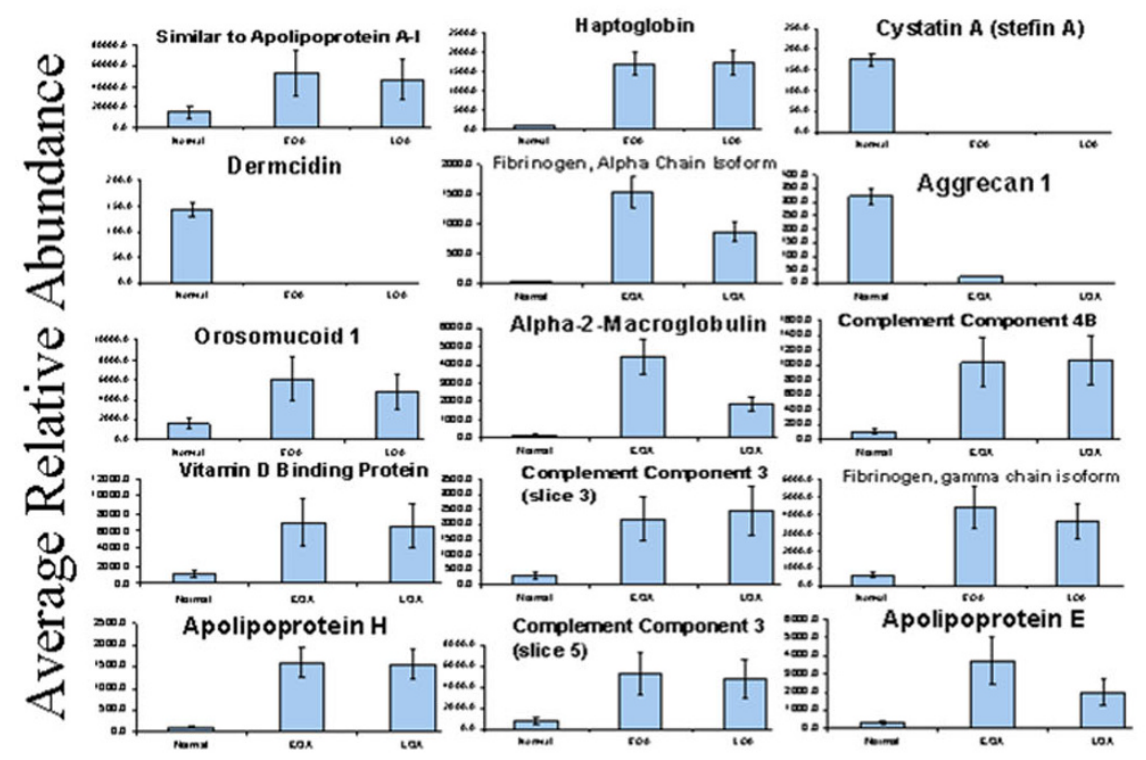

Relative quantitation of biomarkers using total ion current data from mass spectrometry. Determining cutoff values between control individuals and 'diseased' cohorts is among the necessary criteria in identifying protein or gene targets as 'biomarkers'. EOA, early osteoarthritis; LOA, late osteoarthritis.

normal and arthritic chondrocytes [58]. It has numerous proposed functions, including modulation of apoptosis by inhibition of Bax [59]. In situ hybridization demonstrates upregulation of clusterin mRNA after exposure of chondrocytes to oxidative stress, and may represent another pathway by which chondrocytes protect themselves from reactive oxygen and nitrogen species [58]. Paraoxonase 1 is another antioxidant protein whose activity probably mirrors the actvities of the other antioxidants identified in the study. The presence of high concentrations of these species in healthy SF suggests that protection from oxidative stress is of particular importance in the avascular cartilage and highly specialized tissue of the joint lining.

The kallikrein-kinin system has been proposed to play a significant role in the inflammatory processes that underlie OA $[60,61]$. Kallikrein cleaves high-molecular-weight kininogen to yield bradykinin, a potent $\beta_{2}$ agonist on endothelial cells, resulting in the release of prostacyclin and nitric oxide as well as increased vascular permeability via opening of endothelial cell tight junctions and relaxing of smooth muscle [62-64]. We identified two elements of this system, namely kininogen-1 and $\mathrm{N}$-carboxypeptidase, which is a zinc metalloprotease that degrades bradykinin and anaphylactic peptides of the complement system [65]. These observations are congruent with previous work showing that SF contains all of the components needed to generate kinins [66]. It is possible that disequilibrium between the rate of formation and breakdown of kinins results in the inflammation, joint pain, and swelling that are seen in patients with arthritis.
Our analyses identify members of the potently proinflammatory complement cascade, including components $\mathrm{C} 1, \mathrm{C} 3, \mathrm{C} 4, \mathrm{C} 6$ and $\mathrm{C} 8$, as well as complement inhibitory proteins factors $\mathrm{H}$ and I. Although blood (via ultrafiltration) could deliver complement found in SF, numerous groups have demonstrated complement component production by synovial tissue cells [6771]. These observations raise the possibility that synovial tissue generates these abundant protein species locally. Functionally, the complement cascade is implicated in innate immunologic defense of the avascular cartilage and SF as well as in the pathophysiology of both $\mathrm{OA}$ and rheumatoid arthritis $[68,70,72-76]$.

\section{Extracellular matrix and cartilage metabolism}

Numerous extracellular matrix and cartilage metabolism proteins also comprise a significant fraction of abundant soluble proteins in SF. Collagen type VI (a minor species that is found in hyaline cartilage), cartilage oligomatrix protein (a noncollagenous cartilage glycoprotein) and lumican (a member of the small leucine-rich proteoglycans that bind collagen and cartilage intermediate layer protein) are all constituents of either cartilage or synovial tissue extracellular matrix [77-82]. Their presence in high abundance within healthy SF underscores the highly active tissue repair and remodeling that is present in joint tissues. Other proteins associated with cartilage physiology that are present in high abundance in SF include proteoglycan 4 (a lubricating glycoprotein that is homologous to lubricin) and insulin-like growth factor (IGF)-binding proteins (which regulate the activity of the anabolic protein IGF-I). It is 


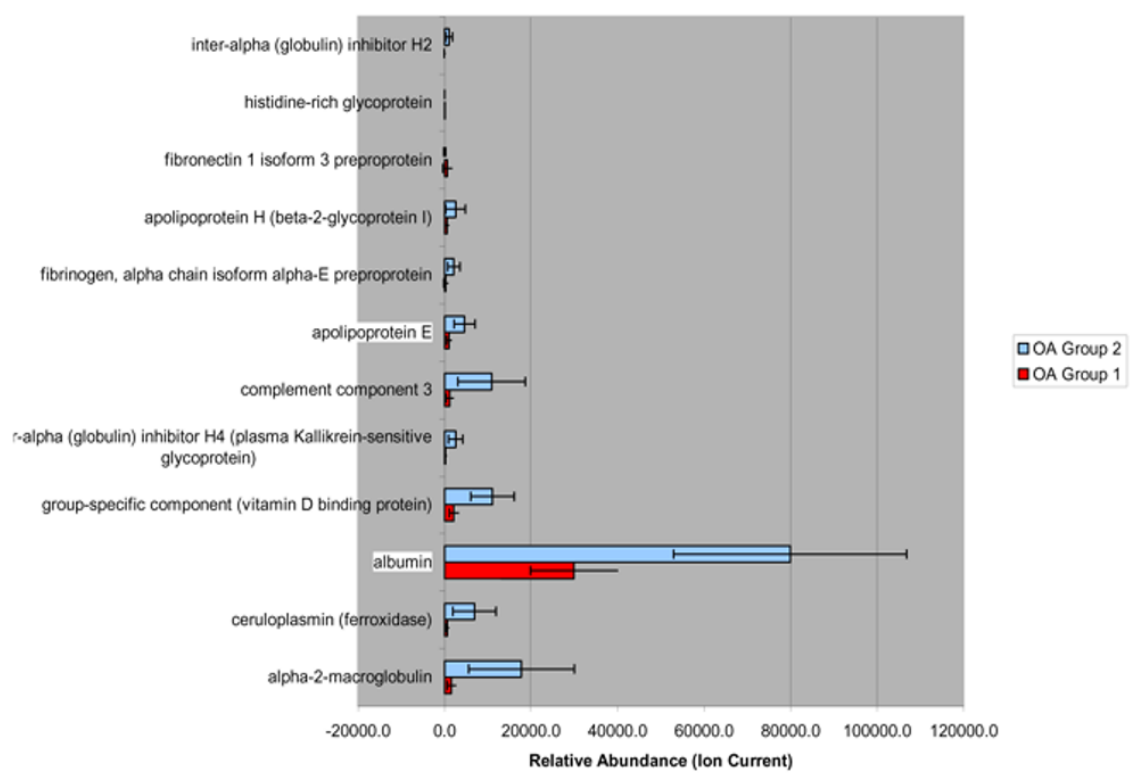

Proteins differentially expressed between two subtypes of osteoarthritis. OA, osteoarthritis.

noteworthy that IGF-I is one of the most important trophic factors for cartilage $[42,83-85]$.

Interestingly, our studies identify a number of protein species that have not previously been appreciated as abundant components of SF. Demonstrating expression of hemopexin, tetranectin, inter- $\alpha$-trypsin inhibitor, histidine-rich glycoprotein, gelsolin, vimentin, and numerous other protein species (Tables 1 and 3) suggests contributions by these classes of protein to SF function. Further analyses of these species promises to provide novel insights into SF physiology in health and disease.

Finally, these pilot data also suggest that differentially expressed abundant protein species in SF could be used as biomarkers for diagnosis and monitoring of therapeutic responses in OA. The ability of these candidate biomarkers to distinguish OA patients from normal individuals adequately will require validation in larger independent cohorts of patients.

\section{Limitations}

Although our studies identify a large number of abundant proteins, a number of anticipated proteins are absent from our list. A striking example is lubricin, a protein whose lubricating properties are critical for both cartilage and synovial lining physiology [11]. Lubricin is present at $200 \mu \mathrm{g} / \mathrm{ml}$ in healthy SF $[10,11]$. Absence of this protein in our studies suggests that our level of sensitivity is less than $200 \mu \mathrm{g} / \mathrm{ml}$, or it could represent a technical limitation of our approach. Lubricin has a $\mathrm{Mr}$ in excess of $200 \mathrm{kDa}$, and penetration of large proteins into the primary PAGE separation technique may limit sensitivity [11].
Our results must be interpreted in light of both of these technical limitations.

Articular cartilage matrix undergoes many changes to its structure, molecular configuration, and mechanical properties with age, including surface fibrillations, increased collagen crosslinking, and alterations in proteoglycan structure [86]. Prevalence studies have shown that after age 40 years the incidence of OA increases with every passing decade [8688]. In an attempt to minimize confounding variables with regard to the analysis of SF from patients with subclinical and preradiographic OA, the control group for this study was chosen from volunteers that were younger than 30 years old. Implicit in this design was lack of age-matched control individuals, because most patients with early and late OA are older than 40 years. In addition, the early OA cohort did not control for patients with inner-third meniscal tears who did not have OA. Finally, the disease-specific performance of these candidate biomarkers was not studied, or were these biomarkers tested against patient populations with varying age, sex, race, or disease etiology (traumatic, infectious, and so on).

Our method of obtaining SF necessitated penetration of the articular space using an 18-gauge needle, a process with obligatory passage through skin and subcutaneous tissue. Our method identified skin-specific keratin species within the abundant proteins in SF. Knowing that these species could only derive from skin, we removed these proteins from our subsequent analyses. The extent of contamination by other skin constituents in our analyses remains undefined. 
Table 3

\begin{tabular}{|c|c|c|c|c|c|c|}
\hline $\begin{array}{l}\text { Serine protease } \\
\text { inhibitors }\end{array}$ & Cartilage metabolism & $\begin{array}{l}\text { Collagen metabolism } \\
\text { cytoskeletal proteins }\end{array}$ & Inflammation & $\begin{array}{l}\text { Immunologic } \\
\text { cascade }\end{array}$ & Oxidative stress & Apoptosis \\
\hline AT III & Fibronectin & Collagen V1 & Fibrinogen & CLIP & Aflamin & Fibrinogen \\
\hline C1 inhibitor & IGFBP & $\alpha_{1}$-Antitrypsin & Kinninogen & $\begin{array}{l}\text { Complement C3/C4/ } \\
\text { C6/C8 }\end{array}$ & Paraoxonase & Vimentin \\
\hline PEDF & Clustrin & Tetranectin & Clusterin & Factor $\mathrm{H}$ and factor $\mathrm{I}$ & $\begin{array}{l}\alpha_{1}-\text { Proteinase } \\
\text { inhibitor }\end{array}$ & Apolipoprotein A \\
\hline$\alpha_{1}$-Antitrypsin & PEDF & Fibronectin & Tetranectin & Fibronectin & Clustrin & $\mathrm{H}_{4}$ inhibitor \\
\hline$\alpha_{1}$-Antichymotrypsin & $\begin{array}{l}\text { Pregnancy zone } \\
\text { protein }\end{array}$ & Gelsolin & $\alpha_{1}$-Acid glycoprotein & Fibrinogen & S100 & \\
\hline Kinninogen & Albumin & SHAP & S100 & $\begin{array}{l}\text { Immuglobulin J } \\
\text { polypeptide }\end{array}$ & & \\
\hline Pregnancy zone protein & CILP & Lumican & PEDF & & & \\
\hline \multirow[t]{4}{*}{$\mathrm{C} 1 \mathrm{q}$ (with $\mathrm{C} 1 \mathrm{~s}$ and $\mathrm{C} 1 \mathrm{r}$ ) } & $\begin{array}{l}\text { Cartilage acidic } \\
\text { protein }\end{array}$ & Vimentin & Apolipoprotein A/E & & & \\
\hline & & COMP & $\begin{array}{l}\text { Complement C3/C4/ } \\
\text { C6/C8 }\end{array}$ & & & \\
\hline & & & Factors $\mathrm{H}$ and $\mathrm{I}$ & & & \\
\hline & & & Carboxypeptidase & & & \\
\hline
\end{tabular}

\section{Conclusion}

Our analyses demonstrate no disease duration-dependent differences in abundant protein composition of SF in OA, and we clearly identify two previously unappreciated distinct subsets of protein profiles in this disease cohort. Additionally, our findings identify novel abundant protein species in healthy SF whose functional contribution to SF physiology was not previously recognized. Finally, these pilot data also suggest that differentially expressed abundant protein species in SF could be used as biomarkers for diagnosis and monitoring of therapeutic responses in OA. The ability of these candidate biomarkers to distinguish OA patients from normal individuals adequately will require validation in larger independent cohorts of patients.

\section{Competing interests}

The authors declare that they have no competing interests.

\section{Authors' contributions}

RG was the principle investigator for this study and oversaw or executed the sample acquisition, data analysis, and drafting of the manuscript. DS assisted in the study design and coordination. AK, MC, and DS participated in the analysis of data. $\mathrm{DL}$ assisted in the analysis of the data and drafting of the manuscript. BK prepared the samples and processed them using the mass spectrometer. All authors read and approved the final manuscript.

\section{Acknowledgements}

We should like to thank Drs Dennis Burke, Thomas J Gill, John Wright, Greg Brick, and John Ready for their gracious support in providing SF samples for our study from their clinical practice. We should also like to thank Laura Previll and Dr James Crish for finalizing the manuscript.

This research received funding from the Arthroscopy Association of North America, the Orthopaedic Research and Educational Foundation, the Harvard Partners Center for Genomics and Genetics, and the Massachusetts General Hospital Bridge Award.

Special acknowledgements are to Dr Raju Kucherlapati for his support of this project at the Harvard Partners Center for Genomics and Genetics and to Christopher Evans for his intellectual support and review of our early manuscript.

\section{References}

1. Brooks PM: Impact of osteoarthritis on individuals and society: how much disability? Social consequences and health economic implications. Curr Opin Rheumatol 2002, 14:573-577.

2. Elders MJ: The increasing impact of arthritis on public health. J Rheumatol Supp/ 2000, 60:6-8.

3. DiCesare PE, Abramson SB: Pathogenesis of osteoarthritis. In Kelley's Textbook of Rheumatology 7th edition. Edited by: Harris ED, Ruddy S, Kelley WN. Philadelphia, PA: Elsevier/Saunders; 2005:2v. (xxix, 1916, Ip)

4. NCBI ftp site [http://ftp.ncbi.nih.gov]

5. Hung KE, Kho AT, Sarracino D, Richard LG, Krastins B, Forrester S, Haab BB, Kohane IS, Kucherlapati R: Mass spectrometrybased study of the plasma proteome in a mouse intestinal tumor model. J Proteome Res 2006, 5:1866-1878.

6. Misra J, Schmitt W, Hwang D, Hsiao LL, Gullans S, Stephanopoulos G, Stephanopoulos G: Interactive exploration of microarray gene expression patterns in a reduced dimensional space. Genome Res 2002, 12:1112-1120.

7. Kho AT, Zhao Q, Cai Z, Butte AJ, Kim JY, Pomeroy SL, Rowitch $\mathrm{DH}$, Kohane IS: Conserved mechanisms across development and tumorigenesis revealed by a mouse development perspective of human cancers. Genes Dev 2004, 18:629-640. 
8. Alter O, Brown PO, Botstein D: Singular value decomposition for genome-wide expression data processing and modeling. Proc Natl Acad Sci USA 2000, 97:10101-10106.

9. Hollander M, Wolfe DA: Nonparametric Statistical Methods 2nd edition. New York: Wiley; 1999.

10. Rhee DK, Marcelino J, Al-Mayouf S, Schelling DK, Bartels CF, Cui Y, Laxer R, Goldbach-Mansky R, Warman ML: Consequences of disease-causing mutations on lubricin protein synthesis, secretion, and post-translational processing. I Biol Chem 2005, 280:31325-31332.

11. Rhee DK, Marcelino J, Baker M, Gong Y, Smits $P$, Lefebvre V, Jay GD, Stewart M, Wang H, Warman ML, Carpten JD: The secreted glycoprotein lubricin protects cartilage surfaces and inhibits synovial cell overgrowth. J Clin Invest 2005, 115:622-631.

12. Wu CC, MacCoss MJ, Howell KE, Yates JR 3rd: A method for the comprehensive proteomic analysis of membrane proteins. Nat Biotechnol 2003, 21:532-538.

13. Washburn MP, Ulaszek RR, Yates JR 3rd: Reproducibility of quantitative proteomic analyses of complex biological mixtures by multidimensional protein identification technology. Anal Chem 2003, 75:5054-5061.

14. Chen El, Hewel J, Felding-Habermann B, Yates JR 3rd: Large scale protein profiling by combination of protein fractionation and multidimensional protein identification technology (MudPIT). Mol Cell Proteomics 2006, 5:53-56.

15. Pratta MA, Su JL, Leesnitzer MA, Struglics A, Larsson S, Lohmander LS, Kumar S: Development and characterization of a highly specific and sensitive sandwich ELISA for detection of aggrecanase-generated aggrecan fragments. Osteoarthritis Cartilage 2006, 14:702-713.

16. Struglics A, Larsson S, Pratta MA, Kumar S, Lark MW, Lohmander LS: Human osteoarthritis synovial fluid and joint cartilage contain both aggrecanase- and matrix metalloproteinase-generated aggrecan fragments. Osteoarthritis Cartilage 2006, 14:101-113.

17. Poole AR, lonescu M, Swan A, Dieppe PA: Changes in cartilage metabolism in arthritis are reflected by altered serum and synovial fluid levels of the cartilage proteoglycan aggrecan. Implications for pathogenesis. J Clin Invest 1994, 94:25-33.

18. Lohmander LS, lonescu M, Jugessur H, Poole AR: Changes in joint cartilage aggrecan after knee injury and in osteoarthritis. Arthritis Rheum 1999, 42:534-544.

19. Rizkalla G, Reiner A, Bogoch E, Poole AR: Studies of the articular cartilage proteoglycan aggrecan in health and osteoarthritis. Evidence for molecular heterogeneity and extensive molecular changes in disease. J Clin Invest 1992, 90:2268-2277.

20. Chambers MG, Kuffner T, Cowan SK, Cheah KS, Mason RM: Expression of collagen and aggrecan genes in normal and osteoarthritic murine knee joints. Osteoarthritis Cartilage 2002, 10:51-61.

21. Morko JP, Soderstrom M, Saamanen AM, Salminen HJ, Vuorio El: Up regulation of cathepsin $\mathrm{K}$ expression in articular chondrocytes in a transgenic mouse model for osteoarthritis. Ann Rheum Dis 2004, 63:649-655.

22. Gabrijelcic D, Annan-Prah A, Rodic B, Rozman B, Cotic V, Turk V: Determination of cathepsins $B$ and $H$ in sera and synovial fluids of patients with different joint diseases. J Clin Chem Clin Biochem 1990, 28:149-153.

23. Lenarcic B, Gabrijelcic D, Rozman B, Drobnic-Kosorok M, Turk V: Human cathepsin B and cysteine proteinase inhibitors (CPIs) in inflammatory and metabolic joint diseases. Biol Chem Hoppe Seyler 1988, 369 Suppl():257-261.

24. Martel-Pelletier J, Cloutier JM, Pelletier JP: Cathepsin B and cysteine protease inhibitors in human osteoarthritis. J Orthop Res 1990, 8:336-344.

25. Abrahamson M, Alvarez-Fernandez M, Nathanson CM: Cystatins. Biochem Soc Symp 2003, 70:179-199.

26. Hou WS, Li W, Keyszer G, Weber E, Levy R, Klein MJ, Gravallese EM, Goldring SR, Bromme D: Comparison of cathepsins $K$ and $S$ expression within the rheumatoid and osteoarthritic synovium. Arthritis Rheum 2002, 46:663-674.

27. Dodds RA, Connor JR, Drake FH, Gowen M: Expression of cathepsin $\mathrm{K}$ messenger RNA in giant cells and their precursors in human osteoarthritic synovial tissues. Arthritis Rheum 1999, 42:1588-1593.

28. Schittek B, Hipfel R, Sauer B, Bauer J, Kalbacher H, Stevanovic S, Schirle M, Schroeder K, Blin N, Meier F, Garbe C: Dermcidin: a novel human antibiotic peptide secreted by sweat glands. Nat Immunol 2001, 2:1133-1137.

29. Rieg S, Seeber S, Steffen H, Humeny A, Kalbacher H, Stevanovic S, Kimura A, Garbe C, Schittek B: Generation of multiple stable dermcidin-derived antimicrobial peptides in sweat of different body sites. J Invest Dermatol 2006, 126:354-365.

30. Ruiz-Romero C, Lopez-Armada MJ, Blanco FJ: Proteomic characterization of human normal articular chondrocytes: a nove tool for the study of osteoarthritis and other rheumatic diseases. Proteomics 2005, 5:3048-3059.

31. Ruiz-Romero C, Lopez-Armada MJ, Blanco FJ: Mitochondrial proteomic characterization of human normal articular chondrocytes. Osteoarthritis Cartilage 2006, 14:507-518.

32. Yoshida K, Suzuki Y, Saito A, Fukuda K, Hamanishi C, Munakata $\mathrm{H}$ : Aggrecanase-1 (ADAMTS-4) interacts with alpha1-antitrypsin. Biochim Biophys Acta 2005, 1725:152-159.

33. Fischer DC, Siebertz B, van de Leur E, Schiwy-Bochat KH, Graeve L, Heinrich PC, Haubeck HD: Induction of alpha1-antitrypsin synthesis in human articular chondrocytes by interleukin-6type cytokines: evidence for a local acute-phase response in the joint. Arthritis Rheum 1999, 42:1936-1945.

34. Beatty K, Bieth J, Travis J: Kinetics of association of serine proteinases with native and oxidized alpha-1-proteinase inhibitor and alpha-1-antichymotrypsin. $J$ Biol Chem 1980, 255:3931-3934.

35. Belcher C, Fawthrop F, Bunning R, Doherty M: Plasminogen activators and their inhibitors in synovial fluids from normal, osteoarthritis, and rheumatoid arthritis knees. Ann Rheum Dis 1996, 55:230-236.

36. Kummer JA, Abbink JJ, de Boer JP, Roem D, Nieuwenhuys EJ, Kamp AM, Swaak TJ, Hack CE: Analysis of intraarticular fibrinolytic pathways in patients with inflammatory and noninflammatory joint diseases. Arthritis Rheum 1992, 35:884-893.

37. Saxne T, Lecander I, Geborek P: Plasminogen activators and plasminogen activator inhibitors in synovial fluid. Difference between inflammatory joint disorders and osteoarthritis. J Rheumatol 1993, 20:91-96.

38. Brommer EJ, Dooijewaard G, Dijkmans BA, Breedveld FC: Depression of tissue-type plasminogen activator and enhancement of urokinase-type plasminogen activator as an expression of local inflammation. Thromb Haemost 1992 68:180-184.

39. Busso N, Peclat V, So A, Sappino AP: Plasminogen activation in synovial tissues: differences between normal, osteoarthritis, and rheumatoid arthritis joints. Ann Rheum Dis 1997 56:550-557.

40. Murphy G, Atkinson S, Ward R, Gavrilovic J, Reynolds JJ: The role of plasminogen activators in the regulation of connective tissue metalloproteinases. Ann NY Acad Sci 1992, 667:1-12.

41. Philip A, Bostedt L, Stigbrand T, O'Connor-McCourt MD: Binding of transforming growth factor-beta (TGF-beta) to pregnancy zone protein (PZP). Comparison to the TGF-beta-alpha 2-macroglobulin interaction. Eur J Biochem 1994, 221:687-693.

42. Clemmons DR, Busby WH Jr, Garmong A Schultz DR, Howell DS, Altman RD, Karr R: Inhibition of insulin-like growth factor binding protein 5 proteolysis in articular cartilage and joint fluid results in enhanced concentrations of insulin-like growth factor 1 and is associated with improved osteoarthritis. Arthritis Rheum 2002, 46:694-703.

43. Lee DM, Kiener HP, Brenner MB: Synoviocytes. In Kelley's Textbook of Rheumatology 7th edition. Edited by: Harris ED, Ruddy S, Kelley WN. Philadelphia, PA: Elsevier/Saunders; 2005:2v. (xxix, 1916, Ip)

44. Close DR: Matrix metalloproteinase inhibitors in rheumatic diseases. Ann Rheum Dis 2001, 60 Suppl 3():iii62-iii67.

45. Egeblad M, Werb Z: New functions for the matrix metalloproteinases in cancer progression. Nat Rev Cancer 2002, 2:161-174.

46. Fassina G, Ferrari N, Brigati C, Benelli R, Santi L, Noonan DM, Albini A: Tissue inhibitors of metalloproteases: regulation and biological activities. Clin Exp Metastasis 2000, 18:111-120.

47. Wojtowicz-Praga S, Torri J, Johnson M, Steen V, Marshall J, Ness E, Dickson R, Sale M, Rasmussen HS, Chiodo TA, Hawkins MJ Phase I trial of Marimastat, a novel matrix metalloproteinase inhibitor, administered orally to patients with advanced lung cancer. J Clin Oncol 1998, 16:2150-2156. 
48. Rasmussen HS, McCann PP: Matrix metalloproteinase inhibition as a novel anticancer strategy: a review with special focus on batimastat and marimastat. Pharmacol Ther 1997, 75:69-75.

49. Nemunaitis J, Poole C, Primrose J, Rosemurgy A, Malfetano J, Brown $\mathrm{P}$, Berrington $\mathrm{A}$, Cornish $\mathrm{A}$, Lynch $\mathrm{K}$, Rasmussen $\mathrm{H}$, et al.: Combined analysis of studies of the effects of the matrix metalloproteinase inhibitor marimastat on serum tumor markers in advanced cancer: selection of a biologically active and tolerable dose for longer-term studies. Clin Cancer Res 1998, 4:1101-1109.

50. Hofmann MA, Drury S, Fu C, Qu W, Taguchi A, Lu Y, Avila C, Kambham N, Bierhaus $A$, Nawroth $P$, et al.: RAGE mediates a novel proinflammatory axis: a central cell surface receptor for $\mathrm{S} 100 /$ calgranulin polypeptides. Cell 1999, 97:889-901.

51. Valencia JV, Mone M, Zhang J, Weetall M, Buxton FP, Hughes TE: Divergent pathways of gene expression are activated by the RAGE ligands S100b and AGE-BSA. Diabetes 2004, 53:743-751.

52. Yan SD, Schmidt AM, Anderson GM, Zhang J, Brett J, Zou YS, Pinsky D, Stern D: Enhanced cellular oxidant stress by the interaction of advanced glycation end products with their receptors/ binding proteins. J Biol Chem 1994, 269:9889-9897.

53. Lander HM, Tauras JM, Ogiste JS, Hori O, Moss RA, Schmidt AM: Activation of the receptor for advanced glycation end products triggers a p21(ras)-dependent mitogen-activated protein kinase pathway regulated by oxidant stress. J Biol Chem 1997, 272:17810-17814.

54. Loeser RF, Yammani RR, Carlson CS, Chen H, Cole A, Im HJ, Bursch LS, Yan SD: Articular chondrocytes express the receptor for advanced glycation end products: potential role in osteoarthritis. Arthritis Rheum 2005, 52:2376-2385.

55. Huttunen $\mathrm{HJ}$, Fages $\mathrm{C}$, Rauvala $\mathrm{H}$ : Receptor for advanced glycation end products (RAGE)-mediated neurite outgrowth and activation of NF-kappaB require the cytoplasmic domain of the receptor but different downstream signaling pathways. J Biol Chem 1999, 274:19919-19924.

56. Jerkovic L, Voegele AF, Chwatal S, Kronenberg F, Radcliffe CM, Wormald MR, Lobentanz EM, Ezeh B, Eller P, Dejori N, et al:: Afamin is a novel human vitamin E-binding glycoprotein characterization and in vitro expression. J Proteome Res 2005, 4:889-899.

57. Ricciarelli $R$, Zingg JM, Azzi A: Vitamin E: protective role of a Janus molecule. FASEB J 2001, 15:2314-2325.

58. Connor JR, Kumar S, Sathe G, Mooney J, O'Brien SP, Mui P, Murdock PR, Gowen M, Lark MW: Clusterin expression in adult human normal and osteoarthritic articular cartilage. Osteoarthritis Cartilage 2001, 9:727-737.

59. Zhang H, Kim JK, Edwards CA, Xu Z, Taichman R, Wang CY: Clusterin inhibits apoptosis by interacting with activated Bax. Nat Cell Biol 2005, 7:909-915.

60. Worthy K, Figueroa CD, Dieppe PA, Bhoola KD: Kallikreins and kinins: mediators in inflammatory joint disease? Int J Exp Pathol 1990, 71:587-601.

61. Bhoola KD, Elson CJ, Dieppe PA: Kinins: key mediators in inflammatory arthritis? Br J Rheumatol 1992, 31:509-518.

62. Pelc LR, Gross GJ, Warltier DC: Mechanism of coronary vasodilation produced by bradykinin. Circulation 1991, 83:2048-2056

63. McIntyre TM, Zimmerman GA, Satoh K, Prescott SM: Cultured endothelial cells synthesize both platelet-activating factor and prostacyclin in response to histamine, bradykinin, and adenosine triphosphate. J Clin Invest 1985, 76:271-280.

64. Colman RW, Stadnicki A, Kettner CA, Adam AA, DeLa Cadena RA Sartor RB: Activation of the kallikrein-kinin system in arthritis and enterocolitis in genetically susceptible rats: modulation by a selective plasma kallikrein inhibitor. Proc Assoc Am Physicians 1997, 109:10-22.

65. Sheikh IA, Kaplan AP: Assessment of kininases in rheumatic diseases and the effect of therapeutic agents. Arthritis Rheum 1987, 30:138-145.

66. Bond AP, Lemon M, Dieppe PA, Bhoola KD: Generation of kinins in synovial fluid from patients with arthropathy. Immunopharmacology 1997, 36:209-216.

67. Neumann E, Barnum SR, Tarner IH, Echols J, Fleck M, Judex M, Kullmann F, Mountz JD, Scholmerich J, Gay S, Muller-Ladner U:
Local production of complement proteins in rheumatoid arthritis synovium. Arthritis Rheum 2002, 46:934-945.

68. Ruddy S, Colten HR: Rheumatoid arthritis. Biosynthesis of complement proteins by synovial tissues. N Engl J Med 1974 , 290:1284-1288.

69. Katz Y, Strunk RC: Synovial fibroblast-like cells synthesize seven proteins of the complement system. Arthritis Rheum 1988, 31:1365-1370.

70. Firestein GS, Paine MM, Littman BH: Gene expression (collagenase, tissue inhibitor of metalloproteinases, complement, and HLA-DR) in rheumatoid arthritis and osteoarthritis synovium. Quantitative analysis and effect of intraarticular corticosteroids. Arthritis Rheum 1991, 34:1094-1105.

71. Breitner S, Storkel S, Reichel W, Loos M: Complement components $\mathrm{C} 1 \mathrm{q}, \mathrm{C} 1 \mathrm{r} / \mathrm{C} 1 \mathrm{~s}$, and $\mathrm{C} 1 \mathrm{INH}$ in rheumatoid arthritis. Correlation of in situ hybridization and northern blot results with function and protein concentration in synovium and primary cell cultures. Arthritis Rheum 1995, 38:492-498.

72. Olmez U, Garred P, Mollnes TE, Harboe M, Berntzen HB, Munthe $\mathrm{E}$ : $\mathrm{C} 3$ activation products, $\mathrm{C} 3$ containing immune complexes, the terminal complement complex and native C9 in patients with rheumatoid arthritis. Scand J Rheumatol 1991, 20:183-189

73. Collard CD, Lekowski R, Jordan JE, Agah A, Stahl GL: Complement activation following oxidative stress. Mol Immunol 1999, 36:941-948

74. Doherty M, Richards N, Hornby J, Powell R: Relation between synovial fluid $\mathrm{C} 3$ degradation products and local joint inflammation in rheumatoid arthritis, osteoarthritis, and crystal associated arthropathy. Ann Rheum Dis 1988, 47:190-197.

75. Corvetta A, Pomponio G, Rinaldi N, Luchetti MM, Di Loreto C, Stramazzotti D: Terminal complement complex in synovial tissue from patients affected by rheumatoid arthritis, osteoarthritis and acute joint trauma. Clin Exp Rheumatol 1992, 10:433-438.

76. Collins T, Winkelstein JA, Sullivan KE: Regulation of early complement components C 3 and C4 in the synovium. Clin Diagn Lab Immunol 1996, 3:5-9.

77. Eyre $\mathrm{DR}, \mathrm{Wu} \mathrm{JJ}$, Apone S: A growing family of collagens in articular cartilage: identification of $\mathbf{5}$ genetically distinct types. J Rheumatol 1987:25-27.

78. Swoboda B, Pullig O, Kirsch T, Kladny B, Steinhauser B, Weseloh $\mathrm{G}$ : Increased content of type- $\mathrm{VI}$ collagen epitopes in human osteoarthritic cartilage: quantitation by inhibition ELISA. J Orthop Res 1998, 16:96-99.

79. Lohmander LS, Saxne T, Heinegard DK: Release of cartilage oligomeric matrix protein (COMP) into joint fluid after knee injury and in osteoarthritis. Ann Rheum Dis 1994, 53:8-13.

80. Saxne T, Glennas A, Kvien TK, Melby K, Heinegard D: Release of cartilage macromolecules into the synovial fluid in patients with acute and prolonged phases of reactive arthritis. Arthritis Rheum 1993, 36:20-25.

81. Hedbom E, Antonsson P, Hjerpe A, Aeschlimann D, Paulsson M, Rosa-Pimentel E, Sommarin Y, Wendel M, Oldberg A, Heinegard D: Cartilage matrix proteins. An acidic oligomeric protein (COMP) detected only in cartilage. J Biol Chem 1992, 267:6132-6136.

82. Knudson CB, Knudson W: Cartilage proteoglycans. Semin Cell Dev Biol 2001, 12:69-78.

83. Jay GD, Tantravahi U, Britt DE, Barrach HJ, Cha CJ: Homology of lubricin and superficial zone protein (SZP): products of megakaryocyte stimulating factor (MSF) gene expression by human synovial fibroblasts and articular chondrocytes localized to chromosome 1q25. J Orthop Res 2001, 19:677-687.

84. Lorenzo P, Bayliss MT, Heinegard D: A novel cartilage protein (CILP) present in the mid-zone of human articular cartilage increases with age. J Biol Chem 1998, 273:23463-23468.

85. Lorenzo P, Neame P, Sommarin Y, Heinegard D: Cloning and deduced amino acid sequence of a novel cartilage protein (CILP) identifies a proform including a nucleotide pyrophosphohydrolase. J Biol Chem 1998, 273:23469-23475.

86. Martin JA, Brown TD, Heiner AD, Buckwalter JA: Chondrocyte senescence, joint loading and osteoarthritis. Clin Orthop Relat Res 2004:S96-S103.

87. Buckwalter JA, Lappin DR: The disproportionate impact of chronic arthralgia and arthritis among women. Clin Orthop Relat Res 2000, 372:159-168. 
88. Buckwalter JA, Mankin HJ: Articular cartilage: degeneration and osteoarthritis, repair, regeneration, and transplantation. Instr Course Lect 1998, 47:487-504. 